Sādhanā Vol. 36, Part 1, February 2011, pp. 65-72. (C Indian Academy of Sciences

\title{
A theoretical approach for the assessment of intralaminar fracture mode and toughness of multilayered composites
}

\author{
P N DILEEP $^{1, *}$ and R RAMESH KUMAR ${ }^{2}$ \\ ${ }^{1}$ Department of Mechanical Engineering, Thangal Kunju Musaliar College of \\ Engineering, Kollam 691 005, India \\ ${ }^{2}$ Honeycomb Product Development Division, Vikram Sarabhai Space Centre, \\ Trivandrum 695 022, India \\ e-mail: dileepkollam@yahoo.com
}

MS received 26 December 2009; revised 15 May 2010; accepted 13 September 2010

\begin{abstract}
Analytical evaluation of fracture toughness of a multilayered composite laminate was well-established using modified crack closure integral (MCCI) approach based on test data on the failure load. For this purpose the crack initiation direction, which is treated as a branch crack direction for the theoretical prediction, is required. The crack initiation direction in a multilayered composite laminate depends on mode of failure. In the present work, a fracture parameter $n^{*}$ is introduced to predict the mode of failure in multilayered composite having a crack and is validated. Analytical relationship for the prediction of fracture toughness of multilayered composite between a base laminate and its constituent sublaminates is also arrived at. With available test data on the toughness of a set of sub-laminates, toughness of base laminate is determined and validated. The present approach is useful in evaluating the load carrying capability of composite structures with defects in the form of cracks and this information is valuable for design.
\end{abstract}

Keywords. Intralaminar fracture toughness; multilayered composites; MCCI approach.

\section{Introduction}

Fibre reinforced composite structures that are extensively used in the aerospace industry have generally very small thickness. Obviously, they are susceptible to damage by tool drops and colliding with stationary objects during handling. Hence, the assessment of residual strength or health monitoring of such structures with damage in the form of a crack has received much attention for the reusable aerospace structural components. Prediction of onset of failure load of brittle composites due to interlaminar and intralaminar fracture was well-established following modified crack closure integral approach, MCCI (Rybicki \& Kanninen 1977).

*For correspondence 
In the modified crack closure integral, the energy integral proposed by Irwin (1958) is transformed into a suitable expression, which can be used with finite element nodal forces and displacements. The approach was successfully demonstrated for 2 and 3-dimensional problems (Badarinarayana et al 1994; Badarinarayana \& Dattaguru 1996). For higher order elements, MCCI approach assumes stress and displacement distributions, which are consistent with the corresponding element shape function (Krishnamurthy et al 1985; Ramamurthy et al 1986). Expressions for higher order elements were also developed by equating the work done by stresses to that by the concentrated forces in closing the corresponding displacements of crack faces in the wake of the crack tip (Raju 1987).

The MCCI approach was applied in the fracture studies of composite laminates with crackpropagation parallel to the fibre direction (Lakshminarayana \& Vishwanath 1994). They evaluated $\mathrm{G}_{c}$ using the experimental results given by Parhizgar et al (1982) for unidirectional CT specimens with fibre angle and initial crack propagation direction normal to the load direction and showed good agreement. But for the angle ply laminates finite element results under estimated the test data and this discrepancy became large for higher values of fibre angle. When the fibres are parallel to the load direction, the deviation was found to be about $23 \%$.

The crack propagation angle with respect to the initial crack is a prerequisite for the prediction of the strength of the composite structures with damage in the form of intralaminar fracture. Recently, an analytical method was proposed to obtain branch crack angle required for MCCI approach by comparing theoretical crack initiation angle with fibre angle in each of multilayered composites (Ramesh Kumar et al 1997). Accordingly, branch crack direction in MCCI approach for a multilayered composite was assumed in the direction of one of the layers whose fibre angle is close to the initial crack direction. This assumption holds well in a general laminate where number of layers for each fibre angle is comparable.

A new empirical relationship has been developed for analytical prediction of fracture toughness of a cross ply laminate based on its constituent laminate (Jose et al 2001). The fracture toughness value of a [0/90] laminate has been predicted based on the toughness values of [0] and [90] constituent laminates.

In the present work, analytical method has been developed for the prediction of fracture toughness of multilayered composite laminate based on the toughness values of its sub-laminates. Once, the fracture toughness values for the sub laminates say, $\left[0^{\circ}\right],\left[90^{\circ}\right]$ and $\left[ \pm 45^{\circ}\right]$ are made available for a given composite material, then the present approach can be used for finding the toughness value of a base laminate made out of any combinations of these sub-laminates. For this purpose, mode-I and mode-II fracture toughness values of sub laminates are computed using MCCI method. The branch crack direction required for MCCI approach depends on mode of failure of the composite laminate. The new fracture parameter defined based on the roots of the characteristic equation of an orthotropic laminate is considered as a factor for identifying the mode of failure of a multilayered composite. Analytical equations are obtained for the prediction of intralaminar toughness of a given laminate based on the toughness of its sub-laminates and are validated by comparing with test data.

\section{Base laminate and sub-laminates}

There can be a set of certain constituent laminates with different fibre orientations called sub-laminates which may represent a base laminate of interest. For instance, a laminate with $[0 / \pm 45 / 90]_{\mathrm{S}}$ construction can be considered as a base laminate and [0], $[ \pm 45]$ and [90] are its 
sub-laminates. Fracture toughness of a base laminate is denoted by capital $\mathrm{K}$ and sub laminates by $\mathrm{k}$.

\section{Present approach}

The characteristic equation of an orthotropic laminate with a center crack is presented in equation (1).

$$
\beta_{11} \mu^{4}-2 \beta_{16} \mu^{3}+\left(2 \beta_{12}-\beta_{66}\right) \mu^{2}-2 \beta_{26} \mu+\beta_{22}=0,
$$

where, $\beta_{i j}$ are the components of the compliance matrix of the laminate. The roots of the characteristic equation are the complex parameters $\mu_{1}$ and $\mu_{2}$. Then a parameter $n$ is defined as (Lekhnitskii 1968),

$$
\begin{aligned}
n & =-\mathrm{i}\left(\mu_{1}+\mu_{2}\right) \\
\text { where, } \quad n & =\sqrt{2\left(\sqrt{\frac{E_{1}}{E_{2}}}-v_{12}\right)+\frac{E_{1}}{G_{12}}} .
\end{aligned}
$$

In the present work, a new parameter $n^{*}$ is defined as a fracture parameter used to identify the mode of failure of a multilayered composite with intralaminar fracture. Note that $E_{1}$ is modulus parallel to the load direction while $\mathrm{E}_{\mathrm{x}}$ in the equation given below is parallel to initial crack direction.

$$
n^{*}=\sqrt{2\left(\sqrt{\frac{E_{x}}{E_{y}}}-v_{x y}\right)+\frac{E_{x}}{G_{x y}}} .
$$

For isotropic material $n^{*}=2$ and the mode of failure is coplanar. Therefore in the present study, for composite materials with coplanar mode of fracture, $n^{*} \geq 2$ is assumed and for noncoplanar mode, $n^{*}<2$ is assumed. For the non-coplanar mode of failure, there should be more of axis fibres with respect to the initial crack direction and hence $n^{*}<2$. If the mode of failure is coplanar, then the branch crack direction $\left(\theta_{c}\right)$ in MCCI approach is taken as $0^{\circ}$ and if the mode of failure is non-coplanar, then $\theta_{c}$ is taken as the fibre angle close to the initial crack direction (Ramesh Kumar et al 1997).

\section{Analytical method of evaluation of intralaminar toughness based on sub-laminate}

The mode-I and mode-II fracture toughness of the base laminate $\left(\mathrm{K}_{I C}\right.$ and $\left.\mathrm{K}_{I I C}\right)$ are represented in terms of its constituent laminate following a method of area-proportioned sum of constituent laminates.

$$
\begin{aligned}
K_{I c} & =\sqrt{\sum_{i}^{n} k_{I_{i}}^{2} * \frac{R_{I_{i}}}{R_{I_{t}}} * \frac{t_{i}}{t}} \\
K_{I I c} & =\sqrt{\sum_{i}^{n} k_{I I_{i}}^{2} * \frac{R_{I I_{i}}}{R_{I I_{t}}} * \frac{t_{i}}{t}},
\end{aligned}
$$


where

$$
\begin{aligned}
& R_{I_{i}}=\frac{\sqrt{\sqrt{\frac{\overline{E_{1}}}{\bar{E}_{2}}}+\frac{\overline{E_{1}}}{2 \bar{G}_{12}}-\bar{v}_{12}}}{\sqrt{2 \overline{E_{1} E_{2}}}} \\
& R_{I I_{i}}=R_{I_{i} \sqrt{\frac{\bar{E}_{2}}{\bar{E}_{1}}}} \\
& K_{c}=K_{I c} \\
& \text { (for coplanar crack initiation) }
\end{aligned}
$$

$$
K_{c}=K_{I c}+K_{I I c}
$$

(for non-coplanar crack initiation),

$k_{I_{i}}$ and $k_{I I_{i}}$ are mode-I and mode-II fracture toughness of the $\mathrm{i}^{\text {th }}$ sub-laminate, $R_{I_{i}}$ and $R_{I I_{i}}$ are constants corresponding to the over all orthotropic properties of $i^{t h}$ sub-laminate. $t$ is associated with the thickness of the base laminate and $t_{i}$ is the thickness of $i^{t h}$ sub-laminate.

\section{MCCI approach for multilayered laminates}

The mode-I and mode-II fracture toughness, $k_{I_{i}}$ and $k_{I I_{i}}$, of the sub-laminates can be evaluated based on modified crack closure integral (Irwin 1958). The crack initiation direction which is used as branch crack angle in MCCI approach is computed based on the simple method presented by Kumar et al (2003a, b). Eight-node quadrilateral layered plate/shell element with three translations and three rotations as degrees of freedom available in NISA is considered for the evaluation of fracture toughness. The failure stress for the laminate available in literature (Cruse 1973; Kumar et al 2003a, b) is applied as a far field stress (figure 1). A fixed boundary condition is applied at the bottom of the model. Using the relationship between the crack tip displacements and nodal forces the fracture toughness can be evaluated (Kumar et al 2003a; Dileep \& Kumar 2005).

\section{Results and discussion}

Initially, the new fracture parameter $\left(n^{*}\right)$ is obtained using equation (3) which will be used to predict the mode of failure as either coplanar or non-coplanar. Table 1 gives $n^{*}$ for the multilayered laminates and is validated for the material set-1 carbon-epoxy laminates by relating the crack initiation direction $\left(\theta_{c}\right)$ values determined by the authors in (Kumar et al 2003a, b). The mode of failure of the $[0 / \pm 45 / 90]$ s carbon-epoxy base laminate is assessed using the Tsai-Hill failure criterion and crack initiation angle for each layer is obtained based on the layer stresses. Out of such angles, the one which is close to the initial crack is considered as the crack initiation and extension angle for the entire laminate (Kumar et al 2003a, b). It may be noted that for laminates having coplanar mode of failure, the crack initiation direction $\theta_{c}$ 


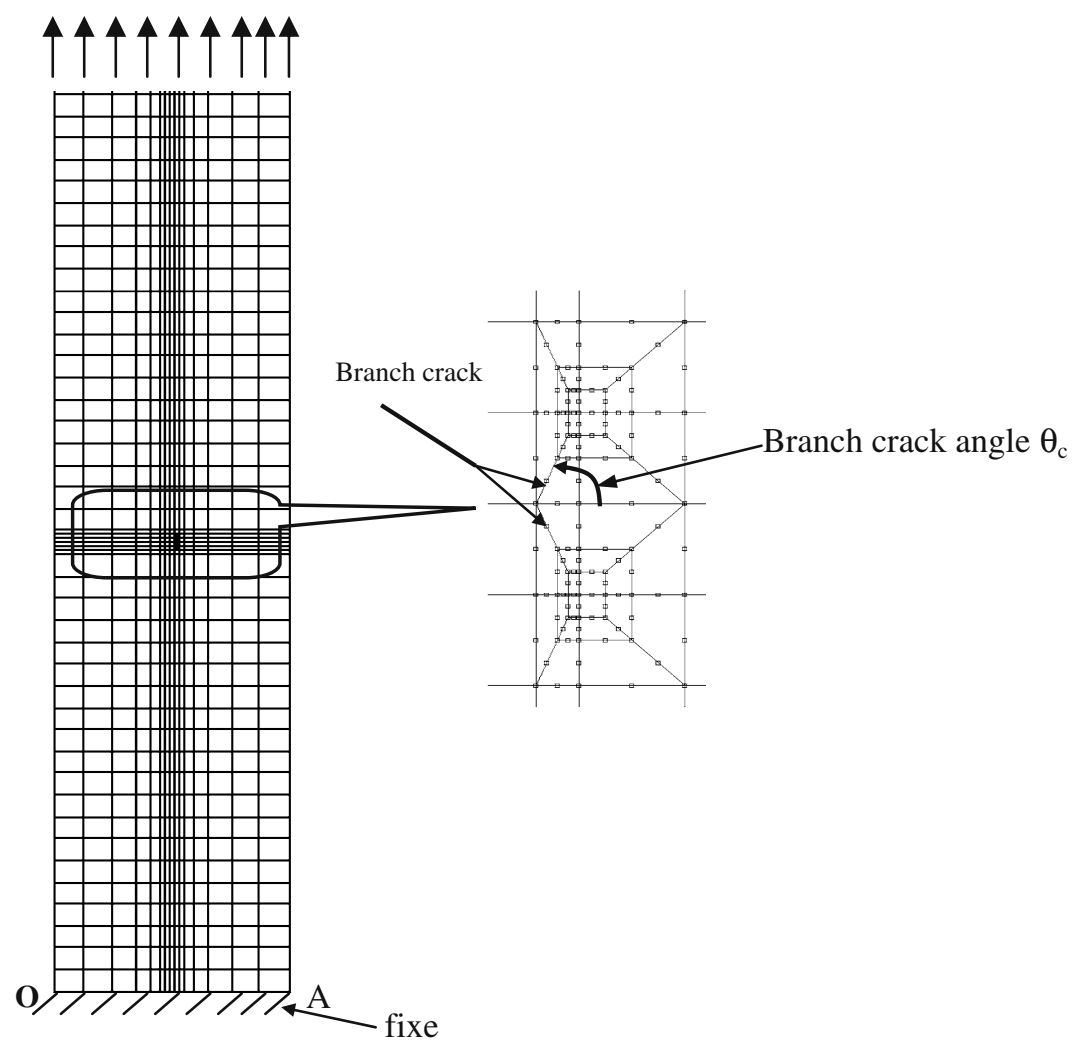

Figure 1. Finite element model for MCCI approach.

is zero degrees and $n^{*}$, for such laminates are found to be $\geq 2$ as expected. From the table 1 for laminates with non-coplanar mode of failure whose $\theta_{c}$ are non-zero, $n^{*}$ is obtained as less than two.

Table 1. The new fracture toughness parameter $\left(n^{*}\right)$ and crack initiation angle $\left(\theta_{c}\right)$ for multilayered laminates.

\begin{tabular}{lcc}
\hline $\begin{array}{l}\text { Laminate } \\
\text { (Material set-1, Kumar et al 2003a, b) }\end{array}$ & $\begin{array}{c}\theta_{c} \\
\text { (Kumar } \text { et al 2003a, b) }\end{array}$ & $\begin{array}{c}n^{*} \\
\text { Eq.(3) }\end{array}$ \\
\hline $\begin{array}{l}\text { Laminate with coplanar mode of failure } \\
{[45 / 90 /-45 / 0]_{\mathrm{s}}}\end{array}$ & $0^{\circ}$ & \\
{$[0 / 90 / 0 / 90]_{\mathrm{s}}$} & $0^{\circ}$ & 2.0 \\
{$[0 / 90 / 0 / 90 / 45 / 90 /-45 / 90]_{\mathrm{s}}$} & $0^{\circ}$ & 3.77 \\
{$[0 / 45 / 0 /-45]_{\mathrm{s}}$} & $0^{\circ}$ & 2.25 \\
Laminate with non-coplanar mode of failure & & 2.48 \\
{$[45 / 90 /-45 / 90]_{\mathrm{s}}$} & $55^{\circ}$ & \\
{$[45 / 90 /-45 / 90]_{2 \mathrm{~s}}$} & $55^{\circ}$ & 1.38 \\
{$[ \pm 45 / 90 / \pm 45 / 90]_{\mathrm{s}}$} & $50^{\circ}$ & 1.38 \\
{$\left[90_{2} / 45 / 90_{2} /-45 / 90_{2}\right]_{\mathrm{s}}$} & $60^{\circ}$ & 1.33 \\
{$[ \pm 45]_{\mathrm{s}}$} & $16^{\circ}$ & 1.44 \\
\hline
\end{tabular}


Table 2. Mode-I and mode-II toughness values of sub-laminates, fracture parameter $(n *)$ and crack initiation angle $\left(\theta_{c}\right)$.

\begin{tabular}{|c|c|c|c|c|}
\hline \multirow{2}{*}{ Sub-laminates } & $\mathrm{k}_{\mathrm{Ic}}$ & $\mathrm{k}_{\text {IIc }}$ & \multirow{2}{*}{$n *$ Eq. (3) } & \multirow{2}{*}{$\begin{array}{c}\theta_{\mathrm{c}} \\
(\text { Kumar et al 2003a, b) }\end{array}$} \\
\hline & $M P a \sqrt{m m}$ & $M P a \sqrt{m m}$ & & \\
\hline \multicolumn{5}{|c|}{$\begin{array}{l}\text { Material set }-1 \text { (Kumar et al } 2003 \mathrm{a}, \mathrm{b}), \mathrm{E}_{1}=129 \mathrm{GPa}, \mathrm{E}_{2}=10.9 \mathrm{GPa} \text {, } \\
\mathrm{G}_{12}=5.65 \mathrm{GPa}, v_{12}=0.31\end{array}$} \\
\hline$[45 / 90 /-45 / 90]_{\mathrm{s}}$ & 1117 & 504 & 1.38 & $55^{\circ}$ \\
\hline$[ \pm 45]_{\mathrm{s}}$ & 707 & 306 & 1.06 & $16^{\circ}$ \\
\hline \multicolumn{5}{|c|}{$\begin{array}{l}\text { Material set }-2(\text { Cruse } 1973), \mathrm{E}_{1}=144.8 \mathrm{GPa}, \mathrm{E}_{2}=11.7 \mathrm{GPa} \\
\mathrm{G}_{12}=4.5 \mathrm{GPa}, v_{12}=0.21\end{array}$} \\
\hline$[0]_{\mathrm{s}}$ & 51 & 0.1 & 6.21 & $0^{\circ}$ \\
\hline$[ \pm 45]_{\mathrm{S}}$ & 490 & 154 & 0.90 & $26^{\circ}$ \\
\hline$[90]_{\mathrm{S}}$ & 895 & 255 & 1.77 & $68^{\circ}$ \\
\hline
\end{tabular}

For the base laminates and sub-laminates considered in the present study, $n^{*}$ values are computed using equation (3) and are presented in tables 2 and 3. Then, using equations (4-7), the fracture toughness of the base laminates is determined based on the sub-laminate values and are compared with the available test data. From table 3 it can be seen that for $[ \pm 45 / 90 / \pm 45 / 90]_{s}$ laminate $n^{*}$ is 1.33 which is $<2$ and hence a non-coplanar mode of failure is expected for the laminate. Hence, for the prediction of toughness value of the base laminate, both $k_{I C}$ and $k_{I I C}$ of the sub laminates are to be computed using MCCI approach. The evaluation of fracture toughness of multilayered laminate with center crack based on MCCI approach was done using the branch crack angle in table 1 .

Comparison of fracture toughness obtained using equations (5) and (6) or (7) with the test data shows a good agreement (table 3 ). The two results compare within 10\%. In the case of $[0 / \pm 45 / 90]_{s}$ laminate $n^{*}$ is 2 as expected and hence for the prediction, mode-I toughness values of the sub-laminates alone are considered. It may be noted that even though the sublaminate fracture mode of $[ \pm 45]_{s}$ and [90] laminates are non-coplanar, for the prediction of the base laminate $[0 / \pm 45 / 90]_{s}$ mode I values of the sub-laminates alone are considered. The comparison of test and predicted values within $10 \%$ is acceptable due to the inherent inhomogeneities in composites.

Table 3. Comparison on fracture toughness prediction using Eq. $(6,7)$ with test data.

\begin{tabular}{lcc}
\hline Base laminate & $\begin{array}{c}\text { Test } \\
\mathrm{K}_{\mathrm{C}} \operatorname{MPa} \sqrt{m m}\end{array}$ & $\begin{array}{c}\text { Prediction } \\
\mathrm{K}_{\mathrm{C}} M P a \sqrt{m m} \\
\text { Eq. }(6,7)\end{array}$ \\
\hline $\begin{array}{l}\text { Material set }-1 \text { (Kumar } \text { et al 2003a, b) } \\
\text { (Cruse 1973; Kumar } \text { et al 2003a, b) }\end{array}$ & & \\
{$[ \pm 45 / 90 / \pm 45 / 90]_{\mathrm{s}}$} & 1532 & 1475, NC mode \\
$n^{*}=1.33 \& \theta_{c}=50^{\circ}$ & & \\
Material set -2 (Cruse 1973) & 718 & 657 C mode \\
{$[0 / \pm 45 / 90]_{\mathrm{s}}$} & & \\
$n^{*}=2.0 \& \theta_{c}=0^{\circ}$ & & \\
\hline
\end{tabular}




\section{Conclusions}

Analytical equations have been derived for the prediction of toughness value of a given multilayered laminate based on the toughness of its sub-laminates. The $n^{*}$ in the present study represents an effective crack initiation direction that can be used in MCCI approach to obtain the toughness value. It is interesting to note that a fracture parameter based on the roots of characteristics equation of composite laminate can give whether mode of failure of the laminate with a crack is coplanar or non-coplanar. A comparison of the predicted toughness values using the mode of failure with test results shows a good agreement and they are within $10 \%$ of each other. Based on the present study, for a composite laminate, fracture toughness values for $\left[0^{\circ}\right],\left[90^{\circ}\right]$ and $\left[ \pm 45^{\circ}\right]$ sub-laminates are once made available then toughness value for different types of base laminates using the sub-laminates failures can be theoretically obtained.

\section{Nomenclature}

$\theta_{c} \quad$ crack initiation angle of the laminate

$E_{x} \quad$ modulus parallel to the crack direction

$E_{y}$ modulus parallel to the load direction

$E_{1} \quad$ modulus parallel to the load direction

$E_{2}$ modulus parallel to the crack direction

$K, k$ toughness of the base and sub-laminates

\section{References}

Badarinarayana K and Dattaguru B 1996 Certain aspect related to computation by modified crack closure integral (MCCI). Eng. Fracture Mech. 55(2): 335-339

Badarinarayana K, Dattaguru B, Ramamurthy T S, Vijayakumar K 1994 A general procedure for modified crack closure integral in 3-D problems with cracks. Eng. Fracture Mech. 48(2): 167-176

Cruse T A 1973 Tensile strength of notched composites. J. Composite Mater. 1: 218-229

Dileep P N, Kumar R R 2005 A simple method for the evaluation of fracture toughness of a multi layered laminate based on the failure stress of sub-laminates. Int. J. Fracture 131(1): L3-L6

Irwin G R 1958 Fracture, Handbuch der Phys., S. Flugge (ed.). Springer-Verlag, Berlin, Vol. VI, pp. 551590

Jose S, Ramesh Kumar R, Jana M K, Rao G V 2001 Intralaminar fracture toughness of a cross-ply laminate and its constituent sub laminates. Composite Sci. Technol. 61: 1115-1122

Krishnamurthy T, Ramamurthy T S, Vijayakumar K, Dattaguru B 1985 Modified crack closure Integral Method for higher order Finite Elements. In Proceedings of the International Conference on Finite Elements in Computational Mechanics; 891-900

Kumar R R, Dileep P N, Renjith S, Rao G V 2003a A simple method for theoretical prediction of fracture toughness of multilayered composites. Advanced Composite Letters 12: 151-158

Kumar R R, Praveen K S, Rao G V 2003b Assessment of delamination fracture load of stringer stiffened composite panel. AIAA J 41: 551-554

Lakshminarayana H V, Vishwanath S 1994 G-evaluation by the MCCI approach: Some recent applications. Lecture notes on the application of fracture Mechanics in Engineering Design, IISc, Bangalore, 149-168

Lekhnitskii S G 1968 Anisotropic Plates. Gordon and Breach Sciences Publications, Inc. New York, USA

Parhizgar S, Zachary L W, Sun C T 1982 Application of the principles of linear fracture mechanics to composite materials. Int. J. Fract. 30: 3-15 
Raju I S 1987 Calculation of strain energy release rates with higher order singularity finite elements. Eng. Fract. Mech. 28(3): 251-274

Ramamurthy T S, Krishnamurthy T, Badrinarayana K, Vijayakumar K, Dattaguru B 1986 Modified crack closure integral method with quarter point elements. Mech. Res. Commun. 13: 179-286

Ramesh Kumar R, Jana, M K, Venkateswara Rao G, Anoop Kumar K S 1997 Accurate evaluation of strain energy release rate in unidirectional FRP compact tension specimen. Eng. Fract. Mech. 58(3): 163-172

Rybicki E F, Kanninen M F 1977 A finite element calculation of stress intensity factors by a modified crack closure integral. Eng. Fract. Mech. 9: 931-938 